\title{
A CALCIUM REVERSAL PHENOMENON: DIFFERENTIATION OF EXCITATORY AND INHIBITORY ROLES OF Ca IN UTERINE SMOOTH MUSCLE CONTRACTION
}

\author{
Kiyoshi SAKAI and Masaatsu UCHIDA \\ Department of Molecular Pharmacology, Meiji College of Pharmacy, \\ Setagaya-ku, Tokyo 154, Japan
}

Accepted January 31, 1980

$\mathrm{Ca}$ ion is known to play dual roles in smooth muscle; an excitatory role in contraction (1-3) and an inhibitory role in membrane stabilization (4). Use of an appropriate blocker should enable differentiation of one role from the other as in the case of adrenoceptors (5). Studies on the differentiation of these two roles of $\mathrm{Ca}$ in smooth muscle contraction were done and our findings are reported herein.

Wistar rats, weighing $170-220 \mathrm{~g}$, were ovariectomized. After a recovery period of 5 days or longer, these rats were given estradiol benzoate s.c. $(0.1 \mathrm{mg} / \mathrm{kg})$ once daily for 3 days and then sacrificed. The uterine horns were removed and mounted in a $30 \mathrm{ml}$ organ bath containing Locke-Ringer's solution aerated with a mixture of $95 \% \mathrm{O}_{2}$ and $5 \% \mathrm{CO}_{2}$ at $30{ }^{\circ} \mathrm{C}$. This solution had the following composition (mM): $\mathrm{NaCl} 154, \mathrm{KCl} 5.63, \mathrm{CaCl}_{2} 2.16, \mathrm{MgCl}_{2}$ 2.10, $\mathrm{NaHCO}_{3} 5.95$, glucose 5.55 (normal solution). Ca free solution was of the same composition, except for the omission of $\mathrm{CaCl}_{2}$. Mechanical responses of the myometrium were recorded on an ink-writing polygraph (RM-45) with a force-displacement transducer, SB-1T in normal solution and SB-1TH in Ca free solution. (SB-1T, SB-1TH and RM-45; Nihon Kohden). SB-1TH is more sensitive than SB-1T, but is not used for recording a tension over $5 \mathrm{~g}$. As oxytocin at $3 \times 10^{-2}$ unit $/ \mathrm{ml}$ induced a tension over $5 \mathrm{~g}$ in normal solution, SB-1T was used to record mechanical responses in normal solution, and SB-1TH in $\mathrm{Ca}$ free solution. The resting tension was $0.5 \mathrm{~g}$ in normal solution and $0.2 \mathrm{~g}$ in $\mathrm{Ca}$ free solution. After an equilibration period of one hour, oxytocin at $3 \times 10^{-2}$ unit $/ \mathrm{ml}$ was applied twice for 15 min periods with a one hour interval. The maximal tension developed was used for normalizing mechanical responses, taking this response as $100 \%(7.6 \pm 0.20 \mathrm{~g}$, $\mathrm{n}=36$ ). Thirty min after the second challenge with oxytocin, the medium was replaced by $\mathrm{Ca}$ free solution with $3 \mathrm{mM}$ EGTA added to deplete the tissue of Ca. EGTA was adjusted to $\mathrm{pH} 7.4$ with $\mathrm{NaOH}$. (EGTA; glycoletherdiaminetetraacetic acid). The incubation time was $50 \mathrm{~min}$, and the force-displacement transducer was replaced by SB-1TH. The solution was replaced by $\mathrm{Ca}$ free solution without EGTA, and after a further incubation for 20 to $30 \mathrm{~min}$, oxytocin $\left(3 \times 10^{-2}\right.$ unit $/ \mathrm{ml}$ in Fig. $1 \mathrm{~A} ; 10^{-2}$ unit $/ \mathrm{ml}$ in Fig. $1 \mathrm{~B}$ and $\left.1 \mathrm{C}\right)$ was applied. Oxytocin induced a sustained contraction, even after extensive Ca depletion by EGTA (Ca free contraction). The magnitude of Ca free contraction was $0.42 \pm 0.024 \mathrm{~g}$ or $5.9 \pm 0.37 \%$ $(\mathrm{n}=12)$ at $3 \times 10^{-2}$ unit/ml oxytocin and was $0.38 \pm 0.020 \mathrm{~g}$ or $4.9 \pm 0.21 \%(\mathrm{n}=24)$ at $10^{-2}$ unit/ml oxytocin. The Ca free contraction was not affected by $3 \times 10^{-6} \mathrm{M} \mathrm{D}-600$, a Ca 
A
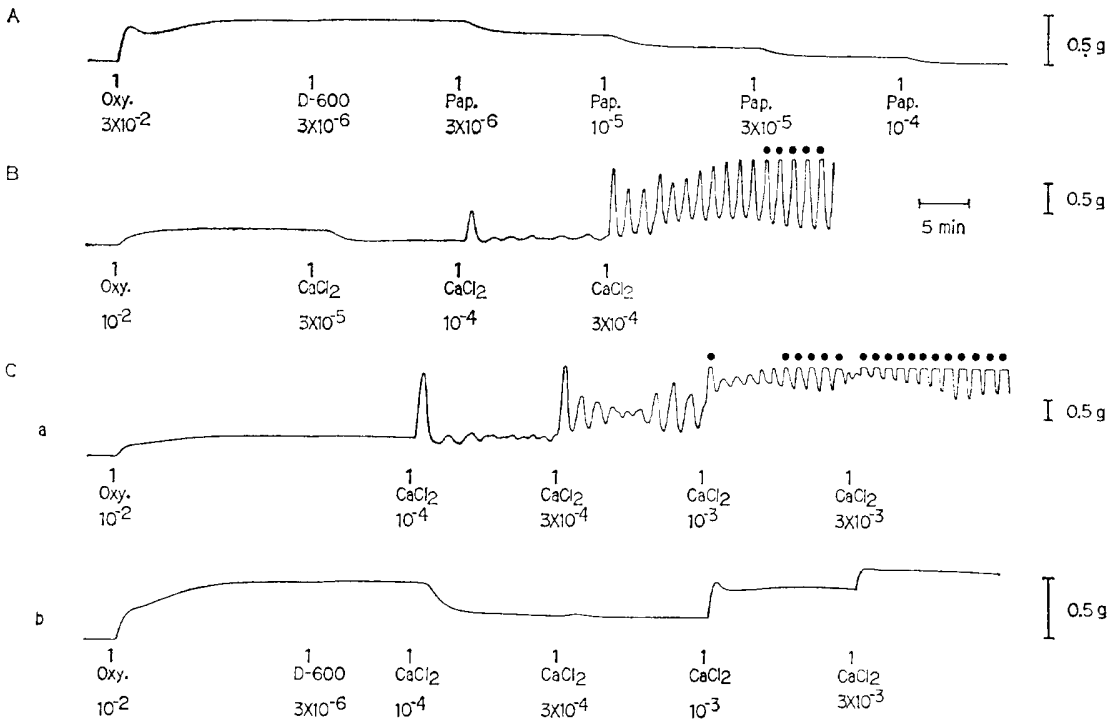

Fig. 1. Oxytocin-induced $\mathrm{Ca}$ free contraction of rat uterine smooth muscle. A; Effect of D-600 and papaverine (Pap.) on Ca free contraction induced by oxytocin (Oxy.). Papaverine was administered cumulatively. B; Effect of exogenously applied $\mathrm{CaCl}_{2}$ on $\mathrm{Ca}$ free contraction. $\mathrm{CaCl}_{2}$ was administered cumulatively. Note the relaxation by a low concentration of $\mathrm{CaCl}_{2}\left(3 \times 10^{-5} \mathrm{M}\right)$. C; Effect of exogenously applied $\mathrm{CaCl}_{2}$ in the absence (a) and presence (b) of $3 \times 10^{-6} \mathrm{M}$ D-600. The two uterine horns were from the same animal. Concentrations of D-600, papaverine and $\mathrm{CaCl}_{2}$ are in molar concentration $(\mathrm{M})$, and that of oxytocin in units $/ \mathrm{ml}$. Dots in Fig. 1B and a of Fig. 1C show over-scaled recordings. Note the differences in the scales of tension.

antagonist (6), but was relaxed by papaverine $\left(3 \times 10^{-6} \mathrm{M}\right.$ or more, Fig. 1A), indicating that intracellular $\mathrm{Ca}$ is utilized during the $\mathrm{Ca}$ free contraction (7). Figure $1 \mathrm{~B}$ and a of Fig. 1C show the effect of exogenous $\mathrm{CaCl}_{2}$ applied during $\mathrm{Ca}$ free contraction. A low concentration of $\mathrm{CaCl}_{2}\left(3 \times 10^{-5} \mathrm{M}\right)$ inhibited the $\mathrm{Ca}$ free contraction and a possible participation of contaminated $\mathrm{Ca}$ in the $\mathrm{Ca}$ free contraction was excluded (Fig. 1B). On raising $\mathrm{CaCl}_{2}$ concentration to $10^{-4} \mathrm{M}$, only one large phasic contraction was evoked and this was followed by a relatively quiescent period and much smaller contractions. A further increase in $\mathrm{CaCl}_{2}$ concentration to $3 \times 10^{-4} \mathrm{M}$ evoked phasic and rhythmic contractions (Fig. 1B and a of Fig. 1C). The contractions evoked by exogenously applied $\mathrm{CaCl}_{2}, 10^{-4} \mathrm{M}$ or over are attributed to an influx of $\mathrm{Ca}$ into the cell as the muscle had been depleted of $\mathrm{Ca}$. The inhibitory effect of low concentrations of $\mathrm{Ca}\left(3 \times 10^{-5} \mathrm{M}\right.$ and possibly $\left.10^{-4} \mathrm{M}\right)$ would then be more manifest if the influx of $\mathrm{Ca}$ is blocked by $\mathrm{D}-600$. Fig. $1 \mathrm{C}$ shows that such is indeed the case. Without pretreatment with D-600 (a of Fig. $1 \mathrm{C}$ ), $\mathrm{CaCl}_{2}\left(10^{-4} \mathrm{M}\right.$ or more) evoked contraction, whereas, with pretreatment with D-600 (b of Fig. 1C), the low concentration of $\mathrm{CaCl}_{2}\left(10^{-4} \mathrm{M}\right.$ ) did not evoke contraction, rather produced a relaxation of the $\mathrm{Ca}$ free contraction. Lanthanum, procaine and quinidine also relaxed the oxytocin-excited $\mathrm{Ca}$ free contraction (data not shown). Ca and all these agents have a membrane stabilizing action (8-10). Thus, the relaxation could be attributed to the membrane stabilizing action of $\mathrm{Ca}$. This action is 
considered to prevail at the $\mathrm{CaCl}_{2}$ concentration of $3 \times 10^{-5} \mathrm{M}$, where, even in the absence of D-600, the $\mathrm{Ca}$ free contraction was relaxed by $\mathrm{CaCl}_{2}$ alone (Fig. 1B). The experiments were repeated on three other preparations with consistent results.

The phenomenon in Fig. 1C is similar to "adrenaline reversal" (11), and thus may be termed "Ca reversal". In "adrenaline reversal", the inhibitory $\beta$-adrenergic effect is unmasked by $\alpha$-blockers. In "Ca reversal", D-600 blocks the influx of Ca utilized for muscle contraction, thus unmasking the inhibitory membrane stabilizing action of $\mathrm{Ca}$. In contrast to the role in muscle contraction (1-3), the role in membrane stabilization is poorly understood. Our findings should contribute to a better understanding of the membrane stabilizing action of $\mathrm{Ca}$.

\section{REFERENCES}

1) Filo, R.S., Bohr, D.F. AND RuegG, J.C.: Glycerinated skeletal and smooth muscle: calcium and magnesium dependence. Science 147, 1581-1583 (1965)

2) Bozler, E.: Control of the contractile mechanism of smooth and cardiac muscle. Am. J. Physiol. 215, 509-512 (1968)

3) Saida, K. And Nonomura, Y.: Characteristics of $\mathrm{Ca}^{2+}$ - and $\mathrm{Mg}^{2+}$-induced tension development in chemically skinned smooth muscle fibers. J. gen. Physiol. 72, 1-14 (1978)

4) BoHr, D.F.: Electrolytes and smooth muscle contraction. Pharmacol. Rev. 16, 85-111 (1964)

5) Nickerson, M.: The pharmacology of adrenergic blockade. Pharmacol. Rev. 1, 27-101 (1949)

6) Fleckenstein, A.: Specific pharmacology of calcium in myocardium, cardiac pacemaker, and vascular smooth muscle. Ann. Rev. Pharmacol. Toxicol. 17, 149-166 (1977)

7) Marshall, J.M. and Kroeger, E.A.: Adrenergic influences on uterine smooth muscle. Phil. Trans. R. Soc. Lond. B. 265, 135-148 (1973)

8) Weiss, G.B.: Cellular pharmacology of lanthanum. Ann. Rev. Pharmacol. 14, 343-354 (1974)

9) Shanes, A.M.: Electrochemical aspects of physiological and pharmacological action in excitable cells. Part I. The resting cell and its alteration by extrinsic factors. Pharmacol. Rev. 10, 59-164 (1958)

10) Weidmann, S.: Effects of calcium ions and local anesthetics on electrical properties of Purkinje fibers. J. Physiol. 129, 568-588 (1955)

11) Dale, H.H.: On some physiological actions of ergot. J. Physiol 43, 163-206 (1906) 